\title{
Aligning needs
}

\author{
Dennis Ford \& William Kohlbrenner \\ The best way for aspiring entrepreneurs to achieve their financing goals is to understand what investors and \\ partners want.
}

\begin{abstract}
f you are an aspiring entrepreneur spinning out a new biomedical technology or launching a biotech startup, one of your first tasks is to understand the funding process and how to tackle it. Five years ago, the accepted investment path was to write a proposal for Small Business Innovation Research (SBIR) grants, hit up a list of friends and family and canvass the local regional angel groups for 'seed' funding. After this first wave of funding, the next money was expected to come from venture capital (VC) entities or through collaborations with partnering companies.
\end{abstract}

What you need to know is that the world has changed, and the investor landscape has morphed. New types of financiers have entered this space, many hoping to accelerate the translation of basic research (Fig. 1). Certain US states now have programs that provide seed funding, with the goal of increasing local startup activity. Some support life science activity in general, such as Massachusetts Life Science Center or New Jersey Economic Development Authority's Technology \& Life Sciences programs, whereas others focus on particular local strengths such as the California Institute of Regenerative Medicine or Cancer Prevention \& Research Institute of Texas. Many US universities are establishing seed funds to benefit their own academic entrepreneurs, following on from similar pioneering efforts in Europe. Research institutions are now also launching commercialization funds and incubators, such as Texas Medical Center's TMCx. Corporate VC efforts have grown, with many pharma, medtech and information technology companies willing to back biotech startups. Family offices of high-net-worth individuals may also make investments in promising

Dennis Ford (Founder \& CEO) \& William Kohlbrenner (CSO) are at Life Science Nation, Boston, Massachusetts, USA. e-mail:dford@lifesciencenation.com companies-whether it be for personal reasons or market opportunity. And there are a growing number of venture philanthropists, patient groups and foundations open to supporting basic research and seed-stage ventures in specific areas.

As CEO or founder of a startup, your goal should be to understand the motivations and desires of all these investor

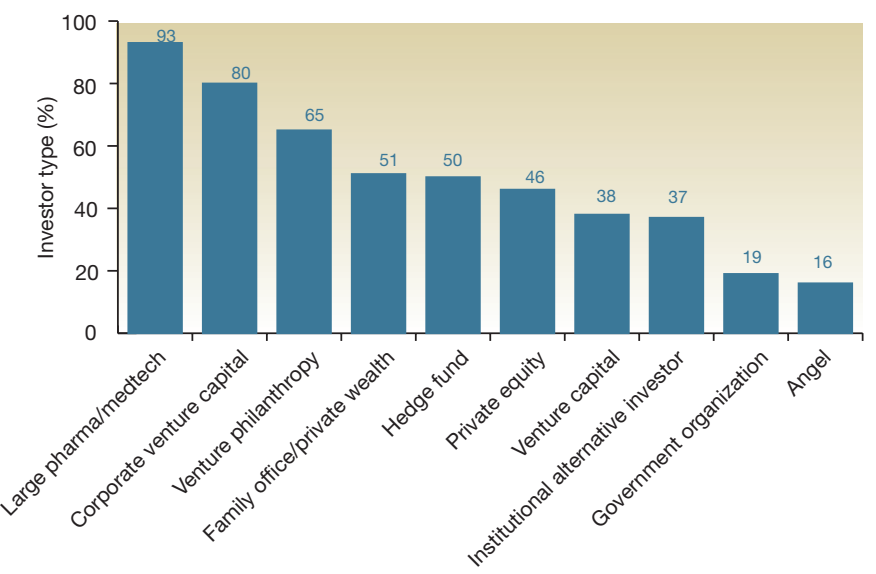

Figure 1 Percentages of each investor type that are seeking opportunities globally. Source: LSN Investor Platform, as of 1 October 2015. types (Table 1), how

they operate and how to approach them. You should learn the individual mandates of each investor, as well as a defined set of 'knockout' factors that could eliminate your company from further consideration (Box 1). This article will help you understand what buyers are looking for before you approach them.

\section{The buyer's mind}

Investors are highly specialized and usually short on time. Remember, your success in attracting funding may correlate more with your technology's development stage, level of risk and extent of validation than with anything else. On the other hand, early-stage opportunities often have a lower cost of buy-in compared with a de-risked but later-stage asset. This allows investors to make multiple bets on several early-stage opportunities instead of just a few, more-expensive ones.

In what follows, we present several key criteria that investors use to quickly evaluate early-stage opportunities. Take heed. Any presentation you make to a group of investors should address each of these criteria.
Management team. Investors want an experienced management team in place before investing. The reasoning, of course, is that seasoned entrepreneurs are thought to have a higher probability of again finding success. Thus, include the names and credentials of the management team. If your core group is young and inexperienced, seek out SBIR grants and collaborate with knowledgeable technical advisors and seasoned business colleagues, as both will help you establish credibility and raise funds. Take the time to recruit older experienced mentors that can fill the businessside holes until the team is intact. This shows a rudimentary understanding to the potential investors, which they need to see.

Unmet need. Investors love products that can satisfy a significant unmet need, as these have the possibility to transform current standards of care and can command a high price tag. Similarly, programs aimed at alleviating so-called orphan diseases receive a great deal of attention from pharmaceutical companies, investors and venture philanthropists because 


\section{Box 1 A knockout game}

Investors are inundated with entrepreneurs soliciting their help, advice and capital. Their goal is to swiftly get compelling opportunities on the table and remove ones that are not a fit.

Below is a list of other reasons why investors can easily disregard your pitch.

- Out of investment scope

- Too early for major investment (lacks validation, too much risk)

- Lacks sufficient IP coverage

- Lack of confidence in management team

- Expensive new product that lacks compelling rationale for replacing lower cost, current standard of care

- New product that brings modest incremental improvements over currently approved products that adequately address medical need.

of their lower regulatory hurdles, their exclusive market or data, and the commercial potential to expand to broader indications after approval. As more and more groups have emerged syndicating support around specific diseases, increased funding is available to find solutions for rare and neglected diseases.

Market fit. Early-stage opportunities targeting established markets (the United States, the
European Union and Japan) are likely to attract more investor interest than opportunities focused on emerging markets. However, there is a subset of investors focused on the emerging market space with the goal of supporting initiatives that address global problems in infectious diseases and other areas.

Early-stage investors are aware that there is enormous pressure to contain and/or reduce the cost of healthcare globally, with institutional (payer) gatekeepers or governments aiming to control access to new therapies and technologies. It will be critical to develop a compelling rationale that justifies a switch from the current standard of care to your premium-priced product. Investors will assume that market uptake of products that bring only incremental improvements may be limited, and they may, therefore, be unwilling to invest in your company.

When speaking to investors about the market for your potential product, don't project

Table 1 Overview of investor classes

\begin{tabular}{ll} 
Investor class & Profile \\
\hline VC & $\begin{array}{l}\text { VC funds are very selective and establish large funds that are used for investing } \\
\text { in a portfolio of companies that they view as having a high probability of success } \\
\text { accompanied by a rapid increase in valuation. They often prefer working with } \\
\text { experienced entrepreneurs. There are VC funds in the early-stage space; many now } \\
\text { focus more on established companies than startups. }\end{array}$ \\
\hline Private equity (PE) & $\begin{array}{l}\text { PE funds typically invest in market-stage companies generating revenues, rather } \\
\text { than startups. However, some PE funds (such as TPG Biotech, Yuanta Asia } \\
\text { Investment and GTCR Golder Rauner) are open to exploring select early-stage } \\
\text { opportunities. A substantial investment is made to buy the company, which is then } \\
\text { restructured and sold at a profit. }\end{array}$ \\
\hline Angel investor & $\begin{array}{l}\text { High-net-worth individuals, with an interest in a particular type of product, service } \\
\text { or industry. These have traditionally been the dominant go-to group for seed fund- } \\
\text { ing of startups. Many are successful entrepreneurs themselves. May join networks } \\
\text { to increase size of investment pool. }\end{array}$ \\
Venture & $\begin{array}{l}\text { Foundations, nonprofits and patient advocacy groups are typically focused on spe- } \\
\text { cific disease areas that provide grants for basic academic research and support the } \\
\text { development of drugs through venture investments. }\end{array}$
\end{tabular}

Hedge fund $\quad$ As yet, only a few active in the early-stage life sciences. Pool of capital from a number of investors, and that is invested in securities and other instruments. Some hedge funds are open to exploring select early-stage opportunities. In such cases, more likely to pool funds with other entities.

Big pharma/ Pharma, biotech and medtech giants devote substantial resources to identifying biotech/medtech development-stage or marketed products that can be introduced into their product portfolios through exclusive in-licensing or company acquisition.

Corporate VC Many large companies allocate funds for investing in early-stage technologies or products that align with their strategic goals. In the life sciences, corporate VC funds typically act as co-investors in financings.

Family office/ private wealth

Institutional

alternative investor that are seeking to diversify their holdings and are open to expanding their portfo-

Represent the collective estate and assets of ultra-high-net-worth individuals. Generally maintain a low profile but have large amounts of capital, a sophisticated institutional investing approach and a long-term outlook. May also have an interest in philanthropy.

Includes financial institutions, pension and endowment funds and other entities lios to include high-risk, high-return opportunities.

Government Government agencies in the USA provide grants to startup companies though the agencies and universities

\section{Investment goal}

VC funds want to invest in promising early-stage companies that have strong potential for an initial public offering (IPO) or that can be sold to a strategic partner, allowing an early investor exit with high return on investment (ROI).

Short-term ROI based on rapid sale of restructured asset.

Investor focus is on companies in the earliest startup stage with the goal of funding promising technologies they view as having high potential value.

Accelerate the development of cures for specific diseases. Some philanthropic groups use an evergreen structure in which ROI is returned to the fund for future work. In other cases it is nondilutive financing. Investment strategies aim to achieve a positive ROI regardless of whether markets are rising or falling.

Obtain exclusive access to products that can be introduced to the market over the near term.

Corporations seek early access to opportunities that can enhance their pipelines over the long term. Achieving a high ROI is not necessarily a major investment goal. They do want home runs, but primarily focus on building a strategically significant portfolio. Investing with the goal of achieving significant ROI, but with a long-term outlook. Some family offices may want to invest early to help stack the odds of helping find a cure for a family disease or malady.

High ROI from key investments over the long term that enhance portfolio value.

The aim of these programs is to help entrepreneurs commercialize promising basic academic research. Typically involves nondilutive funding (government doesn't own part of the company). 


\section{Box 2 Expanding your virtual rolodex}

Well-funded investors are not looking for just a single deal; they are seeking to build a portfolio of investments, and that requires substantial 'deal flow', meaning opportunities are continually evaluated, vetted, prioritized — with the best ultimately funded. To achieve this, many investors attend select conferences, extensive networking activities and industry events - all of which increases their odds of finding the best deals and most compatible investment partners.

Many investors have a web presence, and if a firm is looking for in-bound deal-flow, their website should suggest an initial point of contact, or provide staff profiles that allow an entrepreneur to identify the most relevant person to approach. Take the time to research the investor's portfolio and, if you think you're a close fit for the firm's interests, you can attempt to start a dialog. LinkedIn is also a useful tool for finding staff at investment firms who have experience in your particular area of science.

However, certain investors may not be interested in in-bound deal-flow at all. For example, some family offices prefer to operate in 'stealth mode', and they source opportunities through proprietary networks or preferred syndication partners. More recently, some investors (particularly major life science VC funds) are pursuing 'buildto-buy' investment approaches, in which the investor sources IP directly from a university or research institute and builds an executive team to take the asset towards commercialization, usually spinning out an LLC entity to hold the IP. Some of these investors do not invest in external entrepreneurs at all.

commercial success simply because you are in a particular multibillion-dollar therapeutic space, such as oncology. Rather, detail how you can successfully fit into that market.

Development stage. Because of the poor returns achieved by many early-stage $\mathrm{VC}$ funds over the past decade, many VC funds have shifted their focus to later-stage opportunities, leaving only a small cadre of boutique VC funds catering to the early-stage enterprise. There is no sense in approaching uninterested investors, so you will need to research your investors and make sure that they invest in companies at your development stage and sector.

Validation. Achieving validation of your product raises the value of your company's asset by decreasing risk. Although there may be multiple technical validation steps involved in product development, true validation is when your product performs as designed in a clinical setting; even getting a positive signal in a small phase 2 trial can be enough to boost an asset's value. Investors will want to see in what ways your product has been validated.

Product differentiation. New healthcare products face a competitive, highly regulated market with multiple barriers to entry. You will need to demonstrate the potential to clearly differentiate your product in the target market. That means having a detailed understanding of the commercial landscape you hope to enter-including already marketed products and those in the pipelines of competitors-and then articulating why your product will enjoy meaningful uptake. Doing this will increase your odds of scoring funds.

Intellectual property. Although filing invention disclosures and patent applications can be distracting for bench researchers, it is a front-and-center priority for the scientist entrepreneur. Investors will expect that you have protected your technology with a proprietary intellectual property (IP) position, so be prepared to demonstrate your right to operate in your space. This could mean acquiring an exclusive option to existing IP (university technology or otherwise) or filing relevant patent applications at the earliest stages of company formation. Anticipate an ongoing investment of time and money to strengthen your IP portfolio as the company moves forward. This involves a multiyear process working with the US Patent and Trademark Office and other agencies to get key claims issued and filing additional applications related to novel uses and manufacturing. In addition, you may need foreign filings for protection in of October 1st 2015 global markets. This will require access to experienced (and expensive) legal services.

Strategic alliances. Getting in the door of an investment house is difficult enough; getting access to decision makers in established biotech or pharmaceutical corporations may seem even more daunting. But many of these companies are increasingly looking to partner with academics early in the discovery and development process (the move from $R \& D$ to search and development). And if you can find a partner in industry willing to back your work not only through research funding and operating capital, but also validation of your technology or molecule, investors will take note. They want to see if you have partnerships in place, as both the funding from these deals and the validation they bring can decrease risk for an investor. Decreasing risk can also come from US National Institutes of Health funding. It can come from a partnership with a foundation, patient group or philanthropy helping to move your technology through the development cycle. All of these external collaborations are indicators that others have gauged your technology and found it worth an investment of time and resources.

Innovation plus. You need more than cool science. If you are in the early stages of forming your company and talking to angel investors, then the technical innovations you bring should be the emphasis of those discussions. However, if your company has progressed further, and you are contemplating a major funding round, it's not enough to say you have an innovative platform. Your innovative science should be clearly reflected in an asset that sets you apart from the current market.

Marketing materials. This might seem like a small thing-your handouts, your PowerPoint

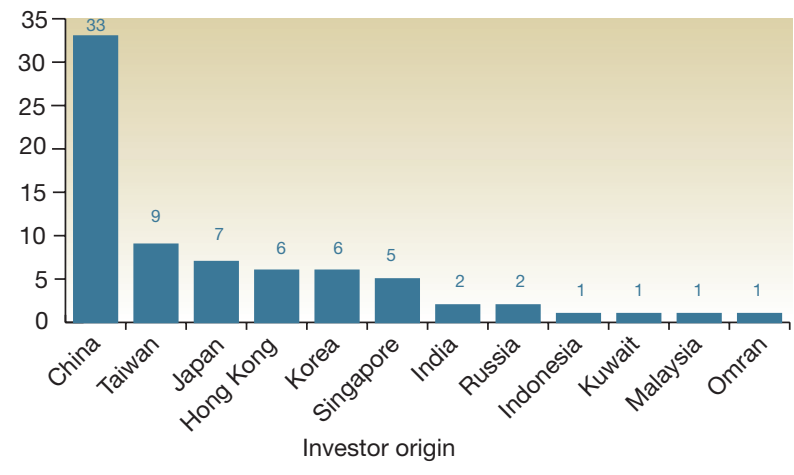

Figure 2 Beyond home shores. Number of Asian investors looking for global opportunities by country. Source: LSN Investor Platform I Data as 
presentations and your web presence. But those are often where investors get their first impressions of both you and your company. Your financing success will in large measure be determined by how skillfully you put together these fund-raising tools, and how you present yourself. Your company may be screened based in part on the quality of your marketing materials.

\section{You and your company}

Life science entrepreneurs who started at the research bench often have little training or experience in marketing and indeed in how to market themselves, let alone a company. The best way we can think of to improve your odds of fund-raising success is: apply marketing and sales concepts to a fund-raising campaign.

The list. Your first step is to generate a list of investors that fit your company's stage and sector (Box 2). We have covered this previously (Nat. Biotechnol. 32, 15-23, 2014), but keep in mind there are $\sim 10,000$ investors around the globe, and $95 \%$ of them probably are not a good fit for you. Doing your homework should drop that number to $300-500$ investors. The goal from there is to do a first pass and get the list chopped down to a 100 or so, and then do more vetting and qualifying until it's down to 30-50. Once you get to that $30-50$, use meetings and phone calls to find out who currently has the ability to give and interest in allocating funds, and reduce it further to 8-12 targets. The next step is reducing it to 3-4 investors who are serious, seeking opportunities and willing to pull the trigger.

This entire process-it's called campaign management-should take you 9-18 months (it's true that some CEOs can raise capital in 6-9 months, but they are the exception rather than the rule). This will take a lot of grunt research, but there are many low-cost cloudbased tools that can help whittle your list down. Automating the tasks of campaign management is key and allows you to track the tasks and interactions associated with each targeted investor.

Branding. Consider that there are many, many opportunities out there for early-stage life science investors. Financiers routinely state that they get hundreds of solicitations coming over the transom per week. As a result, they have gotten quite efficient in how they parse solicitations. They will judge you on (among other things) professionalism, presentation, intelligence and attitude.

Investors will expect you to have done your homework and understand their firm. Investors want to see cogent and lucid presentations that have more than a modicum of forethought and understanding of the task at hand. Branding and messaging that appears nonlinear, helterskelter, too simple or too complex won't impress anyone. An experienced investor might do a cursory parsing of a solicitation in a couple of seconds and a first scan in a couple of minutes, so the easier you make it for them to understand the opportunity that you provide, the better chance you have of receiving a return phone call or e-mail.

Referrals. We cannot emphasize this enough. Referrals can be wondrous door openers. But remember, you will be part of an unfavorable situation if you are referred to an investor and end up not being a fit for their mandate. Investors don't make capital investments simply because of connections, so do not set up meetings simply because you can. Remember that the global life science universe is a relatively small one, and players, from the discovery phase to preclinical/clinical laboratories, right though to commercialization, can overlap as careers morph and companies progress. The people you meet now might in ten years be in new positions. There are good referrals and bad referrals-take the time to know the difference.

Methodology. How is your financing campaign organized? Whether you're deploying an inhouse business development team, or working with an investment bank or third-party marketer, the staff that executes your campaign needs to have an efficient and reliable means of organizing and storing all the relevant data points. We believe that using a cloud-based customer relationship management (CRM) system to organize your campaign is essential. There are many CRM systems available at a low cost (typically \$5-20 per user per month); we use http://www.Salesforce.com (we have no affiliation with Salesforce).

These programs allow you to import your investor target list information from third-party sources (usually through Microsoft Excel), which will create an account page and/or profile for each investor, which then serves as a home for tracking. It offers customized fields for data points related to each investor, such as date of last e-mail, follow up, last voice mail and more.

This allows the campaign team to organize their efforts; indeed, Salesforce.com allows users to automatically track their e-mails to potential investors using the "Email to Salesforce" setting. One benefit of the CRM system is that it can be used as the 'source of truth'; rather than team members spreading information across e-mails, Excel spreadsheets and meeting notes, all information is centralized in the CRM system.,

The information in these systems is useful for managing an in-house fund-raising team, but it's also essential if you are using

\section{Box 3 Looking to the East}

Life science investment used to be a local affair. And indeed, many VCs prefer companies to be based locally so that attending board meetings or catching up with management does not involve flights around the globe. However, in recent years, an increasing number of early-stage investors - particularly investors outside of the traditional hubs like Boston and the Bay Area-are now thinking globally in their deal sourcing and investment efforts. Innovation knows no geographical restriction, and the investment community is acutely aware of this fact. Of the $\sim 950$ investors interviewed by our company Life Science Nation, $45 \%$ are open to investing globally or across multiple continents.

Having interviewed more than 100 Asian-based investors, $75 \%$ of them are open to making investments or to license technologies from outside of Asia. There are several factors leading to this trend. The first is that the current market for life science companies, particularly in the United States, is an attractive one. With the possibility of an IPO for the strongest companies still available, there is potential for a profitable exit. In addition, compared with Asian companies, US and EU life science companies have a stronger support ecosystem for innovation-from strong academic institutions performing discovery research, service providers able to assist in the drug design, development and clinical testing, as well as a larger pool of experienced entrepreneurs well versed in and willing to take new technologies to the market.

Finally, due to the large amount of interested capital in Asia and relatively few investable life science companies, the laws of supply and demand take hold and can drive up the price of Asian deals, making them less attractive than looking for overseas assets. The Asian-based investors we've spoken with generally are most interested in investing with the option to purchase distribution rights in their local geographies, rather than obtaining exclusive global rights to the asset. These groups tend to have strong connections with manufacturers and distribution channels in their regions and can serve as excellent partners in capturing market share in Asia for your product. 
a third-party marketer. We've spoken to life science executives who paid a retainer to an investment bank, but had little insight on what this third party was doing. It's important to know which investors are being contacted, and how frequently. You'll want to see the message a broker sends to investors. CEOs typically hear from their fund-raising partner only when an investor meeting has been booked, but there is so much more to fund-raising than that. A program like Salesforce opens a window on the process.

Lack of adequate follow-up is the number one reason campaigns are not successful. Meeting an interested investor is similar to starting a conversation, and a conversation turns into a relationship only if it is monitored, nurtured and continued. Both parties can get busy, so you will need to make sure someone from your end steps into the breach and feeds this nascent interaction.

\section{Conclusions}

It's important to manage your expectations regarding fund-raising. There is a hierarchy involved, with high-profile academic entrepreneurs at the top, who have multiple successes in building startups and who have relationships with top investors. For these people, a few phone calls may be all that is required to launch a company. However, for most neophyte entrepreneurs, the process will take substantially more time and effort. You must network at scientific meetings and partnering conferences, and keep in mind that many investors are increasingly looking to invest globally, especially investors based in Asia (Box 3 and Fig. 2).

This is not for everyone. So before you start down the path of launching a new enterprise, be sure you appreciate and understand the challenges that any new entrepreneur faces. These challenges can be mastered. The trick is vetting your technology with a network of experts, coalescing a well-rounded team and developing your plan for the business side. Establish a compelling, easy-to-navigate web presence and then identify a global list of investors to go after. Make sure not to underestimate the human resource commitment, and follow up often. Understanding the process, the time commitment and cost to execute a fund-raising campaign is half the battle. Being prepared and in context with the ever-changing cast of characters and the morphing investor landscapemost importantly, what investors are looking for-will allow you to have a far better chance of success.

\section{ACKNOWLEDGMENTS}

The authors would like to thank M. Quigley

(VP, Market Research) and L. Parkinson (Director of Research), both of Life Science Nation, for their contributions in crafting this article.

\section{COMPETING FINANCIAL INTERESTS}

The authors declare no competing financial interests. 